\title{
Spatial Analysis of Social Capital based on Geocoding of Civil Lawsuits
}

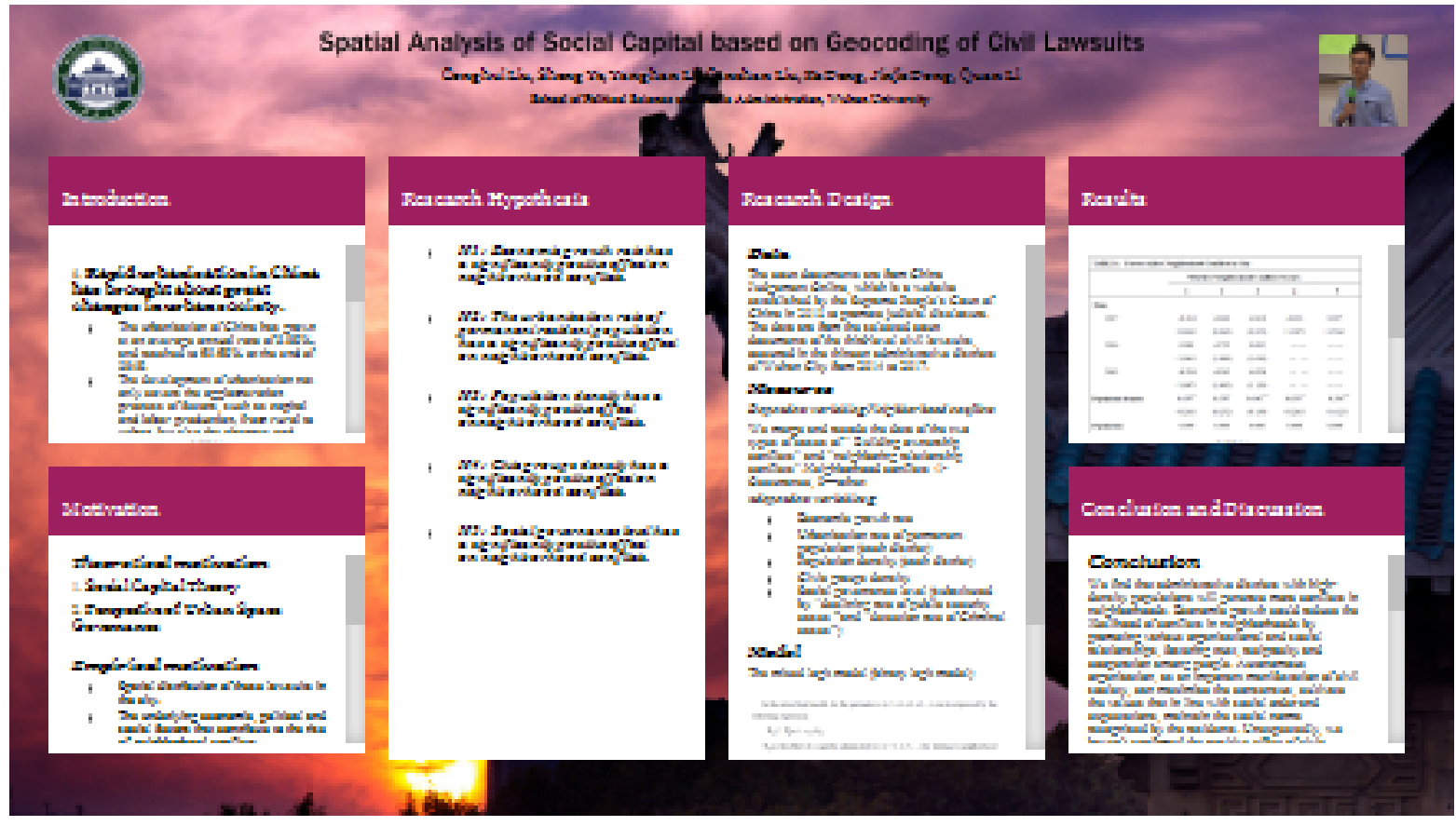

Conghui Liu, Sheng Ye, Yanghan Li, Canshan Liu, Ke Deng, Jinjie Dong, Quan Li School of Political Science and Public Administration, Wuhan University
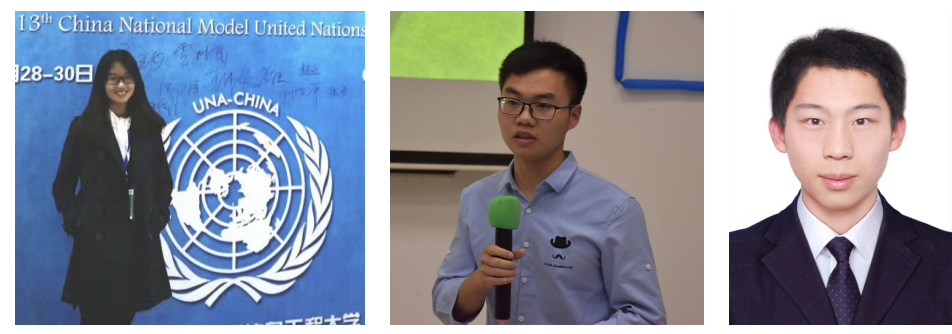

PRESENTED AT:

2019 APSA

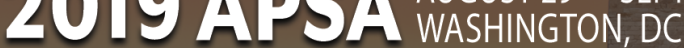






\section{INTRODUCTION}

\section{Rapid urbanization in China has brought about great changes in urban society.}

- The urbanization of China has grown at an average annual rate of $3.08 \%$, and reached to $59.58 \%$ at the end of 2018.

- The development of urbanization not only covers the agglomeration process of factors, such as capital and labor production, from rural to urban, but also the changes and quantity increase of urban spatial structures of different scales (Rrenyi, Song Yingchang, Jiang Jinxing, 2019).

- Urban space, public sector, institutional framework, urban planning, urban culture, and public opinion environment constitute the main factors for the changes of urban structure.

- Changes in China's urban structure may be exacerbating the problems of urban spatial governance and affecting the utility of social capital.

- Urban space governance has become an important policy direction for promoting good social interaction, solving social conflicts, accumulating social capital, and promoting labor reproduction in urban development and community building. It is an important link to improve the modernization of national governance capacities and levels of governance.

\section{Viewing Urban Social Capital from the Perspective of Neighborhood Relations}

- The neighborhood relations portray the network of interpersonal relationships and social trust among neighbors, which reflects the integration of individuals into society and urban community life.

- Social capital is generated from interactions between individuals within civil society (Aldrich, Daniel, and Meyer,2014; Onyx, Jenny, and Bullen,2016). The formation process of urban spatial social capital at the micro level is the process of establishing the trust and norms, and gradually building the social networks in urban residents.

- Neighborhood relations, as the most basic form of individual social networks construction and social embeddedness, should be an important indictor to perspective urban spatial social capital, to some extent, it could predict the overall urban social capital 


\section{MOTIVATION}

\section{Theoretical motivation}

1. Social Capital Theory

2. Perspective of Urban Space Governance

\section{Empirical motivation}

- Spatial distribution of these lawsuits in the city.

- The underlying economic, political and social factors that contribute to the rise of neighborhood conflicts.

- Study the urban social capital from the perspective of neighborhood relations.

\section{Distribution of civil cases in neighborhood conflicts (2014-2017)}

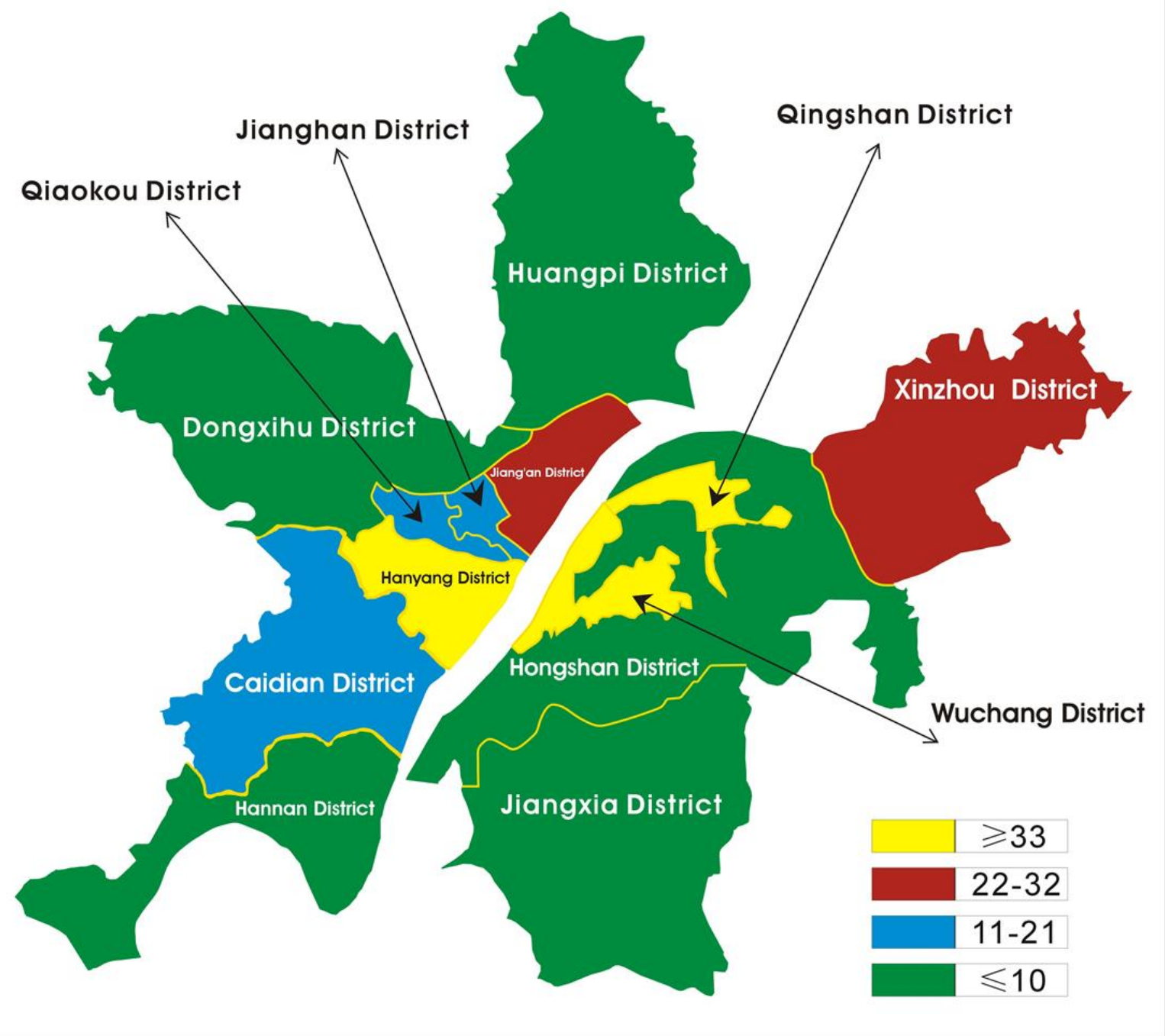




\section{RESEARCH HYPOTHESIS}

- H1: Economic growth rate has a significantly positive effect on neighborhood conflicts.

- H2: The urbanization rate of permanent resident population has a significantly positive effect on neighborhood conflicts.

- H3: Population density has a significantly positive effect onneighborhood conflicts.

- H4: Civic groups density has a significantly positive effect on neighborhood conflicts.

- H5: Social governance level has a significantly positive effect on neighborhood conflicts. 


\section{RESEARCH DESIGN}

\section{Data}

The court documents are from China Judgement Online, which is a website established by the Supreme People's Court of China in 2013 to promote judicial disclosure. The data are from the selected court documents of the third-level civil lawsuits, occurred in the thirteen administrative districts of Wuhan City from 2014 to 2017.

\section{Measures}

\section{Dependent variable: Neighborhood conflicts}

We merge and recode the data of the two types of cases of " Building ownership conflicts" and "neighboring relationship conflicts".Neighborhood conflicts :1-Occurrence, 0 — other.

\section{ndependent variables:}

- Economic growth rate

- Urbanization rate of permanent population (each district)

- Population density (each district)

- Civic groups density

- Social governance level (substituted by "declining rate of public security cases "and "detection rate of Criminal cases")

\section{Model}

The mixed logit model (binary logit model)

In the mixed logit model, for the parameter $\alpha(\alpha=\alpha 1, \alpha 2, \alpha 3, \ldots)$ can be expressed by the following expression:

$$
\mathrm{U}_{i j}=V_{i j}^{\prime} \alpha+\varepsilon_{i j}+\xi_{i j}
$$

$\mathrm{U}_{i j}$ is the effect of a specific administrative $\mathrm{i}(\mathrm{i}=1,2,3, \ldots)$ for leading to neighborhood conflicts $(\mathrm{j}=1,2,3, \ldots), V_{i j}^{\prime}$ is system effect or observable effect, $\varepsilon_{i j}$ is Random effect or unobservable effect.

The selection probability of the mixed logit model is:

$$
\mathrm{P}_{i j}=\int_{\mathrm{K}_{i j}}(\alpha) f(\alpha \mid \theta) \mathrm{d}(\alpha)
$$

$f(\alpha \mid \theta)$ represents the probability density function, and $\mathrm{K}_{i j}(\alpha)$ is the selection probability of parameter $\alpha$ :

$$
\mathrm{k}_{i j}(\alpha)=\frac{e_{i j}(\alpha)}{\sum_{n=1}^{N} e^{v_{n j}(\alpha)}}
$$

The probability expression of mixed logit regression is:

$$
\mathrm{P}_{i j}=\frac{e_{i j}(\alpha)}{\sum_{n=1}^{N} e^{v_{n j}(\alpha)}} f(\alpha \mid \theta) \mathrm{d}(\alpha)
$$




\section{RESULTS}

\section{TABLE 1: Factors Affect Neighborhood Conflicts in City}

\begin{tabular}{|c|c|c|c|c|c|}
\hline & \multicolumn{4}{|c|}{ Whether Neighborhood Conflicts Occurs } & \multirow[b]{2}{*}{5} \\
\hline & 1 & 2 & 3 & 4 & \\
\hline \multicolumn{6}{|l|}{ Time } \\
\hline \multirow[t]{2}{*}{2017} & -0.414 & -0.842 & -0.418 & -0.833 & 0.297 \\
\hline & $(0.844)$ & $(0.862)$ & $(0.853)$ & $(1.387)$ & $(1.536)$ \\
\hline \multirow[t]{2}{*}{2016} & 0.088 & -0.793 & 0.082 & -- & -- \\
\hline & $(1.041)$ & $(1.009)$ & $(1.036)$ & - - & -- \\
\hline \multirow[t]{2}{*}{2015} & -0.224 & -0.343 & -0.230 & -- & -- \\
\hline & $(1.097)$ & $(1.093)$ & $(1.139)$ & - - & -- \\
\hline \multirow[t]{2}{*}{ Population density } & $0.650^{* *}$ & $0.550^{\circ}$ & $0.646^{* \cdots}$ & $0.650^{* *}$ & $0.586^{\cdots *}$ \\
\hline & $(0.261)$ & $(0.252)$ & $(0.139)$ & $(0.261)$ & $(0.123)$ \\
\hline Population- & 0.000 & 0.000 & 0.000 & 0.000 & 0.000 \\
\hline urbanization rate & $(0.000)$ & $(0.000)$ & $(0.000)$ & $(0.000)$ & $(0.000)$ \\
\hline \multirow[t]{2}{*}{ Economic growth rate } & & $-0.188^{*}$ & & & $-0.194^{* *}$ \\
\hline & & $(0.077)$ & & & $(0.082)$ \\
\hline \multirow[t]{2}{*}{ Civic groups density } & & & -0.012 & & 0.128 \\
\hline & & & $(0.510)$ & & $(0.539)$ \\
\hline \multicolumn{6}{|l|}{ Social governance level } \\
\hline \multirow[t]{2}{*}{ Public security cases } & & & & -0.003 & 0.016 \\
\hline & & & & $(0.020)$ & $(0.019)$ \\
\hline \multirow[t]{2}{*}{ Criminal cases } & & & & 0.061 & -0.069 \\
\hline & & & & $(0.168)$ & $(0.187)$ \\
\hline Observations & 353 & 353 & 353 & 353 & 353 \\
\hline $\mathrm{R}^{2}$ & 0.142 & 0.165 & 0.142 & 0.142 & 0.166 \\
\hline \multirow[t]{2}{*}{ Constant } & -4.014 & -1.263 & $-3.913^{* *}$ & -5.823 & -0.909 \\
\hline & $(2.571)$ & $(2.639)$ & $(2.390)$ & $(5.908)$ & $(5.451)$ \\
\hline
\end{tabular}




\section{CONCLUSION AND DISCUSSION}

\section{Conclusion}

We find that administrative districts with high-density populations will generate more conflicts in neighborhoods.

Economic growth could reduce the likelihood of conflicts in neighborhoods by promoting various organizational and social relationships, fostering trust, reciprocity and cooperation among people. Autonomous organization, as an important manifestation of civil society, can maximize the consensus, cultivate the values that in line with social order and expectations, maintain the social norms recognized by the residents. Unexpectedly, we haven't confirmed the positive effect of civic groups density on neighborhood conflicts. We also find that the alternative indicators of social governance level - the decline rate of public security cases and the detection rate of criminal cases — have no significantly impact on the neighborhood conflicts.

\section{Limitation}

- The data used in research are just from Wuhan, and the sample size is small.

- Macro-data is adopted in this research, without taking meso-or micro-data into consideration.

- It's hard to reveal the urban social capital just from the perspective of neighborhood conflicts.

\section{Further consideration}

- How to effectively measure urban social capital?

- What are the changes of urban social capital in recent years?

- How to deduce urban social capital from the perspective of social conflicts?

- What factors lead to the loss of urban social capital? How effectively is the government coping with such matters through both judicial and administrative measures. 


\section{ABSTRACT}

Rapid urbanization in China has created tremendous challenges with respect to building social capital for productive purposes. Stratification among city residents produces contradicting demands with profound social and political implications. Civil lawsuits are growing very rapidly in China and reflect to a great extent the degree of underlying social tensions in cities. We do not know at this point, however, the nature and distribution of such tensions in any of China's urban centers. The release of judicial decisions online enables us to scan and make use of court documents. In our pilot study, we geocoded court opinions from civil lawsuits of neighborhood conflicts in Wuhan, one of China's seven mega cities, for the past decade from 2014 to 2017 . We aim to find first, spatial distribution of these lawsuits in the city. secondly, the underlying economic, political and social factors that contribute to the rise of these conflicts. It is our hope that such an approach could contribute to study the urban social capital from the perspective of neighborhood relations. 